Vol. 68, N. ${ }^{\circ}$ I07 (mayo 2016), 69-88

\title{
DE LA LUCHA POR LA TIERRA A LA DEMOCRATIZACIÓN CONSERVADORA: MOVIMIENTO INDÍGENA Y CAMPESINO EN EL ECUADOR
}

\author{
STALIN HERRERA \\ Instituto de Estudios Ecuatorianos
}

Recepción manuscrito: 15 de marzo de 2016

Aceptación versión final: 29 de abril de 2016

\begin{abstract}
RESUMEN El artículo indaga sobre el proceso de modernización/democratización del campo ecuatoriano y observa que si bien en términos generales éste se caracteriza por ser una modernización conservadora, pues permite que los viejos poderes terratenientes mantengan la propiedad sobre la tierra y diversifiquen su economía, es un proceso complejo con distintas vías regionales. Siguiendo una metodología de la sociología histórica comparada y asumiendo el rol central de las organizaciones indígenas campesinas como actores de los procesos de cambio, se muestran las configuraciones particulares que permitieron una democratización más profunda en la Sierra — provincia de Chimborazo- y un proceso más conservador en la Costa - provincia de Los Ríos.

PALABRAS CLAVE Modernización conservadora, movimiento indígena, movimientos sociales, reforma agraria, democratización.
\end{abstract}

ABSTRACT This article investigates the modernization/ democratization process of the Ecuadorian countryside, and observes that even though, in general terms, this one is known for being a conservative modernization because it lets the old landlord powers keep their ownership over their land and diversify their economies, it is also a complex process with different regional ways. By following a methodology of comparative historical sociology and assuming the central role of the indigenous farming organizations as agents of the change processes, we show the particular configurations that permitted a more profound democratization in the highlands —Chimborazo province - and a more conservative process in the Coast — Los Ríos province-. KEYWORDS Conservative modernization, indigenous movement, social movements, agricultural reform, democratization.

JEL CODES N56, P26, Q1.

\section{INTRODUCCIÓN}

En el Ecuador, como en otras regiones del continente, el movimiento indígena es el actor popular organizado más importante de finales del siglo xx y principios del XXI. ${ }^{1}$ Desde 1990 hasta $2008^{2}$, el movimiento indígena - y los sectores indígenas por extensión- se convirtió en el núcleo de resistencia al neoliberalismo así como de los procesos de democratización de la sociedad. ${ }^{3}$ En 
1996 avanzó en la construcción de estructuras de representación política propias (Movimiento Plurinacional Pachakutic-Nuevo País y partido Amauta Jatari en Chimborazo) que le permitió lograr el control de varios gobiernos locales ${ }^{4}$ y convertirse en la primera fuerza electoral a nivel local. Además se impulsó la constitución de instituciones para la ampliación de derechos indígenas - Salud Indígena, Sistema de Educación Intercultural Bilingüe, Consejo de Nacionalidades y Pueblos del Ecuador - así como para el fortalecimiento del desarrollo local - Fodepi, Ecorae-.

En su momento, y solo comparable con lo ocurrido con los movimientos indígenas de Bolivia, el capital político acumulado, la base social organizada y la articulación con otros movimientos sociales permitió al movimiento indígena ecuatoriano pasar de las acciones insurreccionales a convertirse en una opción política nacional. ${ }^{5}$ Sus demandas y la movilización social impulsaron cambios constitucionales de enorme trascendencia. La constitución de 1998 amplió el reconocimiento de derechos colectivos, mientras que la constitución de 2008 incorporó en su texto lo que podríamos llamar el programa político de los sectores indígenas y campesinos para la sociedad en su conjunto: Buen Vivir, Estado plurinacional, interculturalidad, derechos de la naturaleza, soberanía alimentaria, proscripción del latifundio, desprivatización del agua.

Por su parte, el movimiento campesino de la Costa, a pesar que durante el período que abarcó los años 50 y 70 jugó un rol central en la lucha por la tierra que dio paso a las leyes de Reforma Agraria de 1964 y 1973, hitos de la modernización de campo y el fin del viejo régimen de hacienda, durante los 90 tuvo un papel menor comparado al poderoso movimiento indígena que, paradójicamente, se consolidó a partir de la lucha por la tierra. ${ }^{6}$ Así, los distintos pesos de lo indígena en la Sierra y lo campesino en la Costa, nos muestran que tanto la «modernización» de la sociedad, así como el rol de los indígenas y campesinos en tal proceso, no fueron lineales sino que tienen distintas vías y resultados.

Para Moore (1969), la modernización, ${ }^{7}$ entendida como una ruptura con el viejo régimen terrateniente o hacendatario, ${ }^{8}$ es un proceso de largo aliento caracterizado por relaciones de fuerzas o campos en disputa en los cuales la acción de los indígenas/campesinos y las élites terratenientes, junto a la fortaleza de las instituciones ${ }^{9}$ y la calidad de las alianzas que logran construir con otros sectores, marcan la vía de cambio y sus límites - mayor o menor conservadurismo o democratización de la sociedad-. Aunque para B. Moore (1969), los sectores campesinos no pueden por sí mismos llevar adelante la eliminación del viejo régimen y son las primeras víctimas de la construcción del nuevo «edificio» u orden moderno, éstos tienen la potencialidad de definir la radicalidad de dicho proceso.

Donde se constituyen como una fuerza política de movilización y radicalización han abierto el camino para la construcción de un «capitalismo democrático» como en Francia. Donde las élites rurales no han tenido la suficiente fuerza política, la acción política de los campesinos ha dado paso a revoluciones campesinas que crean los cimientos de sociedades comunistas como Rusia y China. Donde las élites locales han logrado mantener su posición de privilegios y sintonizar sus intereses con los sectores populares, han realizado las revoluciones desde arriba o revoluciones conservadoras que dan paso a regímenes fascistas como Alemania y Japón (Moore, 1969). La intención del presente análisis no es optar por un vía u otra, sino tomar dos elementos propuestos por Moore: i) la modernización es un proceso complejo en el cual los actores - campesinos/indígenas, terratenientes, Estado, burguesías - intervienen de distinta forma y marcan 
los procesos de democratización; y ii) asumir como característica de las revoluciones conservadoras que las élites terratenientes ${ }^{10}$ poseen la capacidad de mantener su posición de privilegios y organizar los cambios o modernización a su favor. Con esas consideraciones, este trabajo sistematiza brevemente los factores que explican el proceso de movilización y éxito del movimiento indígena de Chimborazo para usarlos como guía de interpretación en torno a la desmovilización campesina o escaso protagonismo del movimiento campesino en la provincia de Los Ríos.

\section{CAMBIO Y CRISIS DEL VIEJO RÉGIMEN}

El ícono del viejo régimen en el Ecuador fue la hacienda en la Sierra y la plantación en la Costa. Su origen data de las formas de organización colonial y pervivieron hasta muy entrado el siglo xx. Con la incorporación del Ecuador al mercado mundial (1830) la plantación y la hacienda crecieron reforzando un régimen de explotación basado en el control de la tierra y la fuerza de trabajo indígena/campesina. Aunque en la Costa, dada la escasa población indígena, se desarrollaron relaciones salariales desde muy temprano, la hacienda y la plantación se consolidaron como regímenes de control y de dominio sobre indígenas y campesinos dándole forma al colonialismo interno. Es decir, una estructura de control y explotación que se heredó de la colonia y que no dejo de existir con la independencia, fue central para la reproducción y ampliación de las estructuras de acumulación y reproducción de las élites terratenientes (Casanova, 2006; Burgos, 1997).

En la medida en que la hacienda y la plantación fueron sistemas de producción vinculados a un modelo primario agroexportador, estuvieron sujetos a los ciclos de expansión y crisis del capital: la crisis cacaotera y del Estado oligárquico (1920-1940), así como la recuperación o crecimiento económico (1941-1948) que crea las bases para el auge bananero (1948-1982), se enlazan con varios procesos relacionados con la «modernización de la sociedad»; el ascenso de los gobiernos militares modernizantes (1963-1966; 1972-1976; y 1976-1979) vinculados a la consolidación de un proyecto de industrialización por sustitución de importaciones (ISI) entre 1972-1982 y el ascenso de las luchas campesinas por la tierra ${ }^{11}$ que darán paso a las leyes de Reforma Agraria de 1964 y 1973, constituyen procesos que en su conjunto dan paso a lo que Carlos Larrea define como el Ecuador contemporáneo (Larrea, 1996).

Es importante resaltar que durante los 60 y 70, la lucha por la tierra impulsó el desarrollo y consolidación de las organizaciones campesinas en la Costa y las indígenas en la Sierra. ${ }^{12}$ Hacia los 80, Chiriboga (1986) observa que la organización campesina e indígena cambia, impactada por la presencia del Estado que, desde principios de los 70, bajo el paradigma IsI, venía desarrollando importantes inversiones que tenían como objetivos modernizar la estructura productiva e integrar a los indígenas y campesinos al desarrollo nacional y crear interlocutores con el Estado que pudieran llevar a delante el proyecto. A partir de estas inversiones, las organizaciones indígenas y campesinas demandan mayor autonomía —en relación a las estructuras nacionales y de izquierda - para relacionarse con el Estado y canalizar recursos para la producción. Esta tensión va generando una organización descentralizada y flexible que demanda para si la representación local y territorial. Así, durante los años 80, tanto en el caso de las provincias de Los Ríos y Chimborazo como a nivel regional —Sierra, Costa y Amazonía-, existía una estructura organizativa potente (ver Tabla 1). 
Estas estructuras y redes organizativas habían dejado el estrecho margen de las disputas microlocales y avanzado en formas de organización, representación y coordinación de carácter territorial (cantonales, provinciales) y regional (Costa, Sierra, Oriente); además, gozan de coaliciones partidistas que demandan espacios de representación nacional. Hacia los años 80, hay un entramado organizativo indígena campesino en el que, si bien la «identidad» campesina había dominado las formas de representación, en los 80 las organizaciones también han dado paso a la etnicidad como parte de su configuración organizativa. Una diferencia de adscripción/organización identitaria que en esa década se hace explicita y en los 90 evidente. A raíz de este desarrollo, las organizaciones en la Costa - Los Ríos - optan o mantienen una identidad mayoritariamente campesina y el desarrollo de las organizaciones de la Sierra - Chimborazooptan o desarrollan una identidad mayoritariamente indígena, así se convierten en dos formas de organización dominantes. Así se configuran o consolidan dos formas diferenciadas de organización dominantes regionalmente.

\section{LA VÍA INDÍGENA: CASO CHIMBORAZO}

A finales de los años 70, Burgos (1997) escribe el libro Relaciones interétnicas en Riobamba, el trabajo más importantes sobre las condiciones de marginación y explotación de los indígenas en la provincia de Chimborazo; en él, el autor muestra la fuerza y crudeza con las que las relaciones interétnicas estaban profundamente organizadas por el colonialismo interno que aseguraba mantener a los indígenas en la base de la pirámide de explotación y acumulación de la hacienda.

La hacienda constituía un régimen de dominación y explotación que, más allá del control de la tierra y la mano de obra, extendía sus dominios y mecanismos de control a lo largo del territorio. Además del hacendado, el cual rara vez vivía en la hacienda, la «hacienda» era una estructura de control en la que participaban el Estado, la Iglesia y toda una gama de instituciones no formales que codificadas en relaciones de compadrazgo, lograban la participación activa de varios estratos indígenas en el proceso de explotación. Así, los tinterillos, las chicherías, los mayorales, las arranchadores, se componían de ciertos estratos de indígenas/mestizos que gracias a sus relaciones de compadrazgo con los poderes locales - hacendado, teniente político, curas - obtenían ciertos privilegios y una posición en el sistema explotación a cambio de mantener el control de la población indígena. Esa estructura se constituyó en un fortísimo régimen de control territorial codificado en las relaciones étnicas, pero sobre todo, sostuvo la hacienda como un poder local que ocupaba los distintos espacios de reproducción de la sociedad: la representación política, la reproducción económica y cultural/ideológica (Burgos, 1997).

Sin embargo, treinta años después la posición de la población indígena había cambiado significativamente, el hacendado casi había desaparecido de la narrativa local. ${ }^{13} \mathrm{Si}$ bien el control sobre la gran propiedad como rasgo central del régimen de hacienda parece no haber variado sustancialmente, ${ }^{14}$ se produce una gran democratización de la representación política y la reproducción económica. ${ }^{15}$ Lo más llamativo del proceso es que desde la emergencia del movimiento en 1990 y a lo largo de los últimos 3 o 4 procesos electorales, los indígenas (MUPP-NP, MIAY) se han convertido en la primera fuerza electoral, desplazando a las viejas élites locales blanco-mestizas (ver Tabla 2). 
Tabla 1. Organizaciones en la Costa y Sierra/Amazonía en los 80

\begin{tabular}{|c|c|c|}
\hline NIVELES ORGANIZATIVOS & Costa & SIERRA/AMAZONÍA \\
\hline Coaliciones nacionales & $\begin{array}{l}\text { Frente Unitario por la Reforma } \\
\text { Agraria } 1973 \text { (ACAL, FETAL y FEI) }\end{array}$ & $\begin{array}{l}\text { Coordinadora Campesina Indígena } \\
1983 \text { (FENOC, FEI, ECUARUNARI, } \\
\text { CONACNIE) }\end{array}$ \\
\hline Centrales nacionales & FEI, FENOC & FEI, FENOC \\
\hline Centrales regionales & - & ECUARUNARI, CONACNIE. \\
\hline $\begin{array}{l}\text { Organizaciones regionales y } \\
\text { provinciales }\end{array}$ & $\begin{array}{l}\text { Federación Ecuatoriana de } \\
\text { Trabajadores Agrícolas del } \\
\text { Litoral (FETAL), Asociación de } \\
\text { Campesinos Agrícolas del Litoral } \\
\text { (ACAL) afiliada a la CEDoc, } \\
\text { Asociación de Campesinos } \\
\text { Agrícolas del Ecuador (ACAE) afi- } \\
\text { liada a la CTE, Federación Nacional } \\
\text { de Cooperativas Arroceras } \\
\text { (FENACAPOR). }\end{array}$ & $\begin{array}{l}\text { Comunas tsáchilas, Federación } \\
\text { Shuar, Jatun Cabildo, Federación de } \\
\text { Organizaciones Indígenas de Napo, } \\
\text { los chachis de Esmeraldas forma- } \\
\text { ron una prefederación. }\end{array}$ \\
\hline Provinciales & $\begin{array}{l}\text { Los Ríos: UNCAB } \\
\text { UOCQ (a finales de los } 80 \text { ) }\end{array}$ & Chimborazo: $\mathrm{MICH}, \mathrm{COMPOCIEICH}$ \\
\hline $\begin{array}{l}\text { Partidos políticos de alianza y } \\
\text { representación política }\end{array}$ & $\begin{array}{l}\text { Partido Comunista, Partido } \\
\text { Socialista-FADI }\end{array}$ & $\begin{array}{l}\text { Partido Comunista, Partido } \\
\text { Socialista-FADI, Izquierda } \\
\text { Democrática, Democracia Popular }\end{array}$ \\
\hline
\end{tabular}

Fuente: Ibarra, 1984; Chiriboga 1986; Santos Ditto, 1991 y Guerrero y Ospina, 2003.

A esto podría sumarse el conjunto de instituciones o avances en derechos que el movimiento indígena impulsó, pero basta resaltar que si bien las acciones han sido insuficientes para cambiar las condiciones estructurales de la pobreza, los cambios o avances en términos de bienestar en los gobiernos locales gestionados por los indígenas, fueron más importantes que en otras regiones o gobiernos gestionados por partidos no indígenas (Larrea, 2006). Finalmente, a partir de esto sería interesante preguntarse ¿cuáles son los cambios institucionales —en las relaciones sociales de poder y propiedad, económicos y culturales - que permiten la articulación organizativa y su inclusión política? No existe una sola respuesta, pero la indagación sobre el tema muestra la compleja confluencia de múltiples factores.

\section{PROCESO DE CAMBIO, ALIANZAS EXITOSAS Y AUTONOMÍA}

Para varios autores, el elemento central del proceso de ascenso indígena está relacionado con la transformación de la hacienda y la deselitización de lo local (Burgos, 1997; Carrasco, 1993; Sylva, 1987). Según Sylva (1987), la hacienda tuvo varios procesos de transformación: en los 40, frente al crecimiento de las ciudades, las haciendas intentaron desplazar a los campesinos e indígenas de las mejores tierras y lograron sortear el asedio interno reforzando su control 
territorial; entre los 60 y 70, frente a la presión o lucha por la tierra fueron «cediendo el control político territorial» aunque intentaron reforzar su control sobre las instituciones locales, en mucho casos tuvieron que negociar con las comunidades indígenas el reconocimiento de la tierra en manos de los huasipungos, en otros casos debieron disolverse, pero encontraron en el proyecto IsI no solo el apoyo estatal para su modernización y conversión en industrias lecheras, sino que, sin dejar las mejores tierras, lograron desplazar parte de sus intereses hacia otros sectores y logra su diversificación capitalista (Sylva, 1987).

En este proceso, los sectores indígenas crecieron y fueron ocupando las instituciones locales de la mano de una importante lucha por la tierra que fue apoyada por la acción del Partido Comunista y la Iglesia progresista. Así, más allá de las acciones de movilización, si durante el régimen de hacienda las clases medias blanco-mestizas y la Iglesia eran parte de la estructura de dominación y de control sobre los indígenas, durante los 70 se produjo, en términos de Moore, un cambio de posición de estructuras de dominación. Y aunque los hacendados mantuvieron una alianza conservadora con el Estado e intentaron reforzar su control moral desde las instituciones locales, los sectores indígenas tuvieron alianzas y fuerzas para sostener su avance y su disputa por la tierra hasta entrados los años 90 (Sylva, 1987; Korovkin, 2008).

En los años 70 y 80, la ampliación del Estado a través de los planes y programas de desarrollo fuertemente aprovechados por las comunidades, también buscaron fortalecer la organización en la perspectiva de construir un espacio de interlocución entre el Estado y las comunidades (Ibarra, 1992). Es decir, la relación con el Estado no fue puramente clientelar, sino que además buscó el fortalecimiento de la organización. En este punto es central decir que la acción de la izquierda, la Iglesia, el Estado y, posteriormente, las ONG, así como el propio proceso de diferenciación económica, crearon las condiciones para el surgimiento de organizaciones lideradas por una nueva generación de dirigentes que salieron a disputar la organización y, en términos gramscianos, organizar el discurso y hacer de «lo indio» una afirmación política positiva (Ibarra, 1999; Lentz, 1987).

En los años 8o, si bien la acción de la izquierda que había sostenido la alianza con los campesinos desde los años 30 se debilita y entra en sus propias crisis; el trabajo militante es relevado por la Iglesia — cristiana de izquierda y evangélica protestante- que en Chimborazo levantó toda un red de actores, escuelas, radios comunitarias y catequistas que buscan disputar la conciencia y erradicar las prácticas heredadas de la hacienda - opresión, alcoholismo, autocomplacencia, fatalismo- al punto que la propia Iglesia se indigeniza y la izquierda se cristianiza.

Yo llegué en 1982 [...] aunque con mucha resistencia de la FEI, nosotros entramos a promover la organización indígena; para ese entonces, la acción de la FEI y del Partido Comunista estaba desvirtuada, desgatada en trámites y luchas «legalistas», gastos innecesarios [...] El objetivo con la ECUARUNARI era crear organizaciones alternativas a la izquierda clásica [...]; fue tan fuerte la Iglesia que la misma izquierda empezó a cristianizarse para poder entrar en las comunidades indígenas; apareció en esa época el Frente Revolucionario de Izquierda Cristiana. (Pedro Torres, Riobamba, 11 de noviembre de 2011)

Durante el neoliberalismo (1982-2006), mientras el Estado se retiraba de su rol estratégico, las ONG sirvieron como un espacio complejo y ambiguo: por un lado, muchas de sus acciones tenían la intención de bajar las tensiones en el campo y desmovilizar la acción indígena (Bretón, 
Tabla 2. Alcaldías en manos de partidos indígenas y de izquierda (Chimborazo 2000-2009)

\begin{tabular}{llll}
\hline CANTÓN & 2000 & 2004 & 2009 \\
\hline Alausí & ID/MPD/PS-FA/MUPP-NP & PSP/MIAY & MIAY \\
Chambo & PSC & PSP/CFP & MUPP-NP \\
Chunchi & PRE & DP-UDC/PSC & MLCH/MUPP-NP \\
Colta & MAJ & PSP/MIAY & MUPP-NP \\
Cumandá & ID/MPD/PS-FA/MUPP-NP & PRIAN & MUPP-NP \\
Guamote & MUPP-NP & PSP/MIAY & MIAY \\
Guano & MAJ & PSC/PSP & ID \\
Pallatanga & ID/MPD/PS-FA/MUPP-NP & MUPP-NP & PSP \\
Penipe & MAJ & PSC & PSP/PRE \\
Riobamba & ID/MPD/PS-FA/MUPP-NP & MUPP-NP /MPS & MMIN/MUPP-NP/MPAIS \\
\hline
\end{tabular}

Fuente: Elaboración propia a partir de datos del Consejo Nacional Electoral.

2006 y 2008; Ibarra, 1996); por otro lado, no es menos cierto que sirvieron como un espacio para canalizar recursos que demandaba el creciente procesos organizativo indígena (Ospina, et al. 2008 y Ospina, 2009).

Los sectores indígenas, si bien no logran la fuerza suficiente para avanzar en la lucha por la tierra, tenían una estructura organizativa y de alianzas potente. Así, aunque la intervención del Estado, la acción de las ONG y su propia acción no fueron suficientes para eliminar la pobreza, evitar los procesos de diferenciación y la movilidad poblacional alrededor del crecimiento de las ciudades, la condición étnica — entendida como la fortaleza comunitaria- fue de enorme importancia para sostener y levantar las acciones de protesta frente a los poderes terratenientes y al propio Estado.

Casi sin anunciarlo, en junio de 1990 los indígenas inauguran la década con un gran levantamiento que puso un millón de personas en las calles. En la provincia de Chimborazo, entre 150.000 y 200.000 personas - aproximadamente el 70\% de la población rural de la provincia- se movilizaron durante siete días (Korovkin, 2008, p. 179). A partir de ese momento, las organizaciones que se habían constituido en la lucha por la tierra durante los 70 y consolidado en su disputa por los recursos estatales en los 80 , se plantean un nuevo proceso organizativo: el movimiento indígena - encabezado por la CONAIE-, de gran éxito durante los 90 y parte de la década del 2000.

\section{LA VÍA CAMPESINA: CASO LOS RÍOS}

En comparación con la Sierra, Los Ríos era una zona «despoblada» o de pequeños pueblos dispersos, pero con una enorme «disponibilidad» de tierras. La dispersión y limitada presencia indígena hizo difícil a las élites locales construir mecanismos efectivos de control de la mano de obra. A lo largo de su historia, esa misma característica de la región impidió que el régimen de plantación fuera una estructura tan rígida como la hacienda en la Sierra. La migración indígena Sierra-Costa abrió una fuente inestable pero permanente de trabajadores sobre 
la cual los hacendados establecieron otros mecanismos de control basados en salarios y favores de protección, «una compleja combinación de relaciones de producción no capitalista con uso de trabajo asalariado» (Silverman, 1986, p. 82).

Sin decir que el sistema de control y dominación de la población no fue represivo, los indígenas y poblaciones de la Costa se «incorporaron» o asimilaron rápidamente en la dinámica comercial y productiva de la región, lograron mucha movilidad, capitalizaron sus esfuerzos y mantuvieron pequeñas propiedades. Para muchos migrantes de la Sierra atraídos por los salarios, a pesar de las condiciones insalubres y la falta de «saber productivo» para adaptarse a las inclemencias del trópico, la migración a la Costa se convirtió en una opción económica importante, una estrategia que les permitía acumular algunos ingresos para volver a sus comunidades y comprar tierras, convertirse en comerciantes y, en muchos casos, terminar asentándose en la Costa (Ronn, 1994, p. 262; Burgos, 1997).

Sin embargo, a pesar de que los sectores campesinos gracias a la crisis de los años 30 , que obligó a las élites a replegarse, lograron avanzar en la ocupación de tierras y el control de algunos mercados. Pero con el boom bananero, así como con la extensión de la caña de azúcar y los ingenios - más tarde la palma - en la Costa se consolidó un modelo de gran propiedad y el delta del río Guayas se convirtió no solo en la cuna de los «oligarcas del cacao», sino en el nuevo eje de acumulación agroindustrial y el centro de las agroexportaciones (Chiriboga, 1980; Cueva, 1981; Uggen, 1993; Guerrero, 1994). Resultado fue la expansión del modelo de gran propiedad y un nuevo avance de los terratenientes sobre la tierra y las familias campesinas, pero al mismo tiempo las organizaciones crecieron al punto de empujar con éxito las leyes de reforma agraria (1964 y 1973) y de convertirse en los años 80 en una alternativa política local - según algunos testimonios, en los 80 el Frente Amplio de Izquierda (FADI) fue una alterativa electoral en Vinces y Baba-. Contradictoriamente, aunque la lucha de las organizaciones campesinas en torno a la tierra fue importante y logró un importante entramado organizativo, no logró sobrevivir a la avanzada de la gran propiedad. Asombra cómo, a diferencia de Chimborazo, hacia principios del siglo xxi las organizaciones campesinas carecen de representación política y la mayor parte de los municipios quedaron en manos de los partidos tradicionales, viejos representantes de las élites terratenientes (ver Tabla 3).

Aunque la Tabla 3 puede dar una idea errada en torno a la presencia del Movimeinto PAIs -que para las elecciones de 2009 se presenta como una opción popular y de izquierda-, en el trabajo de campo se observa cómo los espacios de representación y las estructuras de decisión o representación de Movimiento PAIs fueron ocupados por los viejos partidos de derecha (PSC, PRE, PRIAN), desplazando las posiciones más democráticas del naciente movimiento (Herrera, 2009). Así, aunque la lucha por la tierra persistió hasta entrados los 90 (North, et al., 2008; Uggen, 1993; y Dubly, 1993), las organizaciones campesinas no lograron una expresión política que pudiera vincularse al naciente movimiento indígena que marcó la década de los 90 y tuvo la fuerza para promover una representación electoral propia. En este sentido, la interrogante continúa: ¿Cuáles fueron los factores por los cuales los campesinos no logran constituir una fuerza que lleve adelante la tarea de eliminar el viejo régimen y posicionar su agenda? 
Tabla 3. Alcaldías en manos de partidos de izquierda y centro (Los Ríos 2000-2009)

\begin{tabular}{llll}
\hline CANTón & 2000 & 2004 & 2009 \\
\hline Baba & PSC & PRE & MPAIS \\
Babahoyo & PSC & PSC & MPAIS \\
Buena fe & PRE & PRIAN & MPAIS \\
Mocache & PSC & PSC & PSP \\
Montalvo & ID & ID & MPAIS \\
Palenque & PRE & PSP & PRE \\
Pueblo viejo & PSC/MFLPP & PRE & MPAIS \\
Quevedo & PSC & PSC & MPAIS \\
Urdaneta & PSC & PRE & MPD \\
Valencia & PRE & PRE & MPAIS \\
Ventanas & PRE & PRE & PSP \\
Vinces & PSC & PRIAN & MPAIS \\
\hline
\end{tabular}

Fuente: Elaboración propia a partir de datos del Consejo Nacional Electoral.

\section{PROCESO DE CAMBIO Y SUBORDINACIÓN CAMPESINA}

Al igual que Chimborazo, la articulación entre la izquierda y las organizaciones campesinas fue un proceso importante y poderoso, de hecho, más temprano, importante y poderoso que en la Sierra, pero aprobada la Ley de Reforma Agraria, el contexto para las movilizaciones y el proceso organizativo cambió. El retorno de la gran propiedad que había iniciado en los años 40 no se detuvo con la Ley de Reforma Agraria, éste se constituyó en un retorno agresivo y violento que enfrentó las organizaciones a sangre y fuego. Las élites terratenientes se tomaron las instituciones locales para la aplicación de la reforma agraria — primero el Instituto Nacional de Colonización y luego el Instituto Ecuatoriano de Reforma Agraria y Colonización, IERACy lanzaron una avanzada paramilitar sobre las tierras que estaban ocupadas por los campesinos, manteniendo la lealtad y complicidad de la policía y los militares.

Esa historia se repitió en otras organizaciones y cooperativas; bueno, se logró conseguir esos pedacitos de tierra, en algunos casos hasta con sangre, pérdidas de vidas humanas. En otros casos, nosotros hasta fuimos enjuiciados y encarcelados porque en estos lados el poder terrateniente era bastante fuerte y la autoridad también estaba de su lado: el político, comisario, gobernador, también intendente, los jueces. Entonces, hubo una muy fuerte persecución y represión. Los hacendados tenían a su favor a los del IERAC y eso hacía que la lucha se volviera mucho, mucho más dura. A los cultivos nuestros metían los caballos, el ganado de ellos. En definitiva, fue una lucha muy dura, un compañero de la cooperativa Jagual, aquí cerca, lo mataron; al compañero Inocente Franco un luchador de los mejores, a ése lo mataron, y de ahí hubieron [sic] muchas cosas más. (Armando Merchán, dirigente de la unOCAR, Vinces, 6 de febrero de 2011)

Frente a la fuerza terrateniente y la complicidad con las instituciones del Estado, la alianza con las organizaciones de izquierda no fue suficiente. A diferencia de la Sierra, la comunidad 
campesina no logró fortalecer su base comunal y convertirse en un espacio de resistencia a la gran propiedad. ${ }^{16} \mathrm{Al}$ contrario de esto, la falta o debilidad de lazos comunales las hizo más permeables a la interiorización de las relaciones del capital o los procesos de individualización.

[...] Yo creo que el problema es el tema más organizativo [cultural]. Las organizaciones se quedaron, y las que han logrado aprovechar están vinculadas al tema de la Sierra, no es el montubio, es la gente indígena que es más comunitaria, hay un grupo indígena superfuerte [...]. Ése es un tema organizativo propio de la Sierra [...], acá había un tema de organización propia, no de derecho pero sí de hecho, no muy comunitario. (Lucía Delgado, extécnica de PROLOCAL, Pueblo Viejo, 15 de junio de 2011)

Paralelamente, aunque las organizaciones de izquierda fueron la alianza organizativa y política más importante, éstas no lograron fortalecerse en el tiempo o lograr un recambio organizativo. Si bien lograron generar alianzas con los sectores medios de las ciudades y fortalecer una propuesta sindical, ésta no tuvo la fortaleza para contener la encarcelación y persecución de sus dirigentes con la que los distintos gobiernos intentaron persuadir a las organizaciones de izquierda y la «amenaza comunista», así como la competencia entre las propias organizaciones de izquierda, y sus divisiones, por la organización del campo.

[...] Las organizaciones fuertes duraron hasta el 8o, por decir. El liderazgo del PC era fuertísimo, sí fue fuerte. Y la organización también se mantuvo por el liderazgo y la conducción del Partido Comunista. Pero ahí también aparece el MPD y ahí comenzó una ruptura entre chinos y cabezones. Me acuerdo [de] que la disputa por la CTE, entre chinos y cabezones. Y también me estaba olvidando, en ese tiempo en la dictadura militar (1963-1966) apareció la CEDOC [...] Entonces nosotros también fuimos a pedir ayuda a la CEDoc pensando que ahí nos iban a perdonar el ser comunistas, nada [...] ya nos tenían anotados. (Eliodoro Indio, Quevedo, 6 de febrero de 2011)

La acción de la Iglesia de los pobres no fue tan fuerte como en la Sierra, su estructura no tuvo la fortaleza para hacer el recambio organizativo y perdieron el apoyo de las instituciones eclesiales que en los 90 se hizo más conservadora.

En las comunidades eclesiales de base hay una especie de desencanto, fueron importantes [en los Ríos] en algún momento de la historia, en la época de los 70 y 80, incluso 90, pero han ido perdiendo protagonismo sin el apoyo de la Iglesia oficial. [...] Las comunidades están en un estado de hibernación porque no tienen apoyo de la institución eclesial, las comunidades y las organizaciones de pobres tienen muchos cercos, si no tienen apoyo se debilitan. (Benjamín Raspaliza, Cura de Palenque, 19 de mayo de 2011)

Así, las organizaciones campesinas, a pesar de que sus núcleos importantes sobrevivieron (FEI del Partido Comunista, FENOcin del Partido Socialista y sus filiales uocQ en Quevedo y UNOCAR en Vinces), no lograron ampliar su base social y a pesar de la fortaleza con la que la Iglesia de los pobres trabaja en la zona (Pueblo Solidario en Palenque, Baba y Vinces), ésta tampoco logró constituirse en el recambio de la izquierda. 
Las acciones del Estado y las ONG, al igual que en la Sierra, lograron con mucho éxito impulsar a las organizaciones, pero el resultado no se tradujo en una mayor autonomía de estas frente al mercado y los poderes locales. Inicialmente los proyectos fortalecieron tanto la iniciativa de las organizaciones como su infraestructura productiva, y mejoraron su posición frente al mercado, pero con la implementación del neoliberalismo, la retirada del Estado los dejó endeudados, sin el soporte económico-técnico, ni la capacidad para competir frente a la agroindustria.

Con el foderuma (Fondo de Desarrollo Rural Marginal), ahí había más o menos apoyo para los campesinos para que desde una finca mixta que había cacao, maderables, plátano, yuca, o sea, la finca diversificada se tumbó y la gente sembró maíz. Las organizaciones se fortalecieron con el FoDERUMA, se pidió préstamos a la banca privada y se les dio a las asociaciones. ¡Tomen para que trabajen! Pero los campesinos no pudieron pagarlos, los cultivos no rindieron o no quisieron. Después, la uoce tuvo que vender muchos de sus activos para pagar las deudas, por ejemplo, la casa de la esquina que era de la UocQ. Tenía infraestructura, tractor grande, secadora, todo eso se vendió. (Vicepresidenta de la UocQ, Quevedo, o6 de febrero de 2011).

Los relatos muestran que la alianza con el Estado y las ong fue inestable y contradictoria. Las organizaciones dieron los pasos hacia el crédito, la asistencia técnica, la mecanización, la infraestructura productiva y la comercialización, lo que constituiría finalmente su «modernización». A la larga, el resultado fue que los campesinos pasaron de ser productores diversificados a monoproductores de arroz y maíz; de economías campesinas «autónomas» a agriculturas campesinas subordinadas al precio del mercado y a las cadenas productivas para la exportación. Aunque el proceso de modernización e incorporación de los campesinos al mercado creó un proceso de diferenciación económica, en el marco de una izquierda y estructura organizativa débil, éste no se tradujo en un proceso de diferenciación política o el desarrollo de una capa de intelectuales propios con la fuerza para salir a disputar un proyecto campesino y democratizar el entorno político. Lo cierto es que las organizaciones de izquierda, la Iglesia y los mismos dirigentes campesinos debieron soportar y sortear el entorno político e institucional represivo que se desarrolló en Los Ríos y la «moderna agroindustria».

Cinco de la tarde. Tanto me recuerdo todita esa vaina cuando estaba el carro lleno de policías. Cuando nosotros llegamos con el último carro cargado de banano, nadie se mueve, a los 5 principales dirigentes nos tenían. Ahí, sucio hecho, una sola vaina, ¿qué podíamos hacer? Porque: que señor, que por aquí, que por allá. Nada. «¡Vamos!, más luego van a cantar», decían. «iComunistas»!, decían. Nos llevaron allá a la hacienda [... ] Al mero palo, a encapucharnos, a meternos en un tanque de agua, con un cabo de hacha nos daban. "ii Qué, son comunistas ustedes?! ¿Qué hacen con el comunismo?». Yo: «¿Qué es comunismo? Yo no sé nada de comunismo». «Ah, ¿no sabes?» «iTan!, ¡tan!, ¡pas!» nos daban. [...] Entre ellos mataron a uno porque siempre a los dirigentes los han perseguido toda la vida. Usted ya sabe, camarada. (Eliodoro Indio, dirigente de la CTE, Quevedo, 2 de febrero de 2011)

Tal como lo muestran los trabajo de Dubly (1993) y North et al. (2008), durante los años 80 y 90 la lucha por la tierra no desapareció, aunque no tuviera la dimensión social que en los 70, 
el conflicto se presentó reproduciendo los mismos patrones históricos que en los 60 y 70: hacendados que despojan a campesinos usando la violencia abierta o contratando bandas paramilitares resguardados por la complicidad abierta del sistema de justicia y la policía. Los estudios de Martínez (2003), Rubio (2010) y Jácome et al. (2008), muestran que con la expansión de la agroindustria - bananera y cañera-, las relaciones salariales no significaron una mayor ampliación de las instituciones democráticas, sino que configuraron una estructura privada igualmente represiva que a través de sistemas informales de control laboral - listas negras de trabajadores que denuncian abusos, la intermediación salarial, amenazas de despido, flexibilización laboral, uso de mano de obra infantil - mantienen una disciplina férrea y contienen el conflicto en las esferas privadas de la gran plantación.

Finalmente, en el trasfondo del cambio, la gran diferencia de la provincia de Los Ríos con Chimborazo es que las «élites terratenientes» no abandonaron sus intereses en el campo, sino que integraron a los distintos estratos de la sociedad a sus necesidades, actualizaron/modernizaron sus mecanismos clientelares de control, así como ocuparon todos los espacios de reproducción social, cultural, política y económica. Tal como lo plantean los dirigentes, las élites lo controlan todo.

[...] Ya no tienen organización; toda esta organización lo que dura es un período porque todos los dirigentes de estas organizaciones han sido víctimas del asistencialismo de los gobiernos de turno, en cada gobierno algunos dirigentes han ido hipotecando las organizaciones [...] El asistencialismo, el populismo, el caciquismo aquí de familias que han controlado políticamente a la provincia y han incidido, estamos hablando de los Andrade, los Duma, los Marún han controlado; entonces esos son los que han concentrado políticamente y han controlado las organizaciones. (Robert Alvarado, Quevedo, 8 de febrero de 2011).

Sin embargo, el proceso de actualización y modernización de las élites locales fue más lejos, tuvieron la capacidad para sintonizar sus intereses con los de la sociedad en su conjunto. Por un lado, al igual que en la Sierra, dejaron su condición puramente terrateniente y diversificaron su fuentes de acumulación pero sin abandonar sus intereses en el campo. Por otro lado, se han convertido en estructuras que controlan las distintas esferas de la producción, circulación y consumo. Un ejemplo clásico es el Grupo Noboa del magnate Álvaro Noboa, que fue dueño de la hacienda bananera más grande del mundo, La Clementina (10.0oo ha), pero además mantiene intereses o empresas en las esferas del procesamiento de alimentos, la exportación de alimentos y la importación de insumos (ver Tabla 4).

Pero Álvaro Noboa es más que un empresario próspero con inversiones en otras esferas de la producción, al igual que otros grupos, compite por los espacios de representación política siendo el representante máximo del Partido de Reconstitución Institucional Álvaro Noboa (PRIAN). Así, como se observa en la tabla 5, cuando los dirigentes y organizaciones campesinas dicen que los hacendados lo «controlan todo», se refieren a un hecho: las élites económicas o grupos económicos despliegan todas sus capacidades para ocupar los distintos espacios, no solo de reproducción económica, sino de representación política.

Si bien la tabla 5 no logra mostrar toda la capacidad de influencia de las élites terratenientes, tiene la intención de ilustrar dos cosas: i) los «hacendados» ocupan importantes cargos de 
Tabla 4. Empresas e intereses del Grupo Noboa en la agroindustria Grupo Noboa

\begin{tabular}{|c|c|c|}
\hline $\begin{array}{l}\text { AGROINDUSTRIA DE PRO- } \\
\text { DUCCIÓN Y PROCESA- } \\
\text { MIENTO DE ALIMENTOS }\end{array}$ & $\begin{array}{l}\text { AGROINDUSTRIA TRADICIONAL AR- } \\
\text { TICULADA A LA EXPORTACIÓN }\end{array}$ & $\begin{array}{l}\text { PRODUCCIÓN E IMPORTA- } \\
\text { CIÓN DE AGROQUÍMICOS }\end{array}$ \\
\hline $\begin{array}{l}\text { Industrial Molinera, } \\
\text { Molinos Poultier S. A., } \\
\text { Ultramares Corporación } \\
\text { C. A., Compañía Ganadera } \\
\text { El Tejano S. A., Ganadera } \\
\text { Río Playón S. A., Ganadera } \\
\text { San Rafael S. A. (GARASA), } \\
\text { Pesquera Marintan S. A. }\end{array}$ & $\begin{array}{l}\text { BANACONT s. A., Compañía de Elaborados de } \\
\text { Café C. A. (ElCAFE C. A.), Compañía Agrícola } \\
\text { la Julia s. A. (CALAJUSA), Industrial Bananera } \\
\text { Álamos S. A., Exportadora Bananera Noboa S. } \\
\text { A., Compañía Agrícola Loma Larga S. A. (CA- } \\
\text { LOLASA), Compañía Agrícola Río Ventanas } \\
\text { S. A. (CARIVESA), Compañía Agrícola Ángela } \\
\text { María S. A. (CAAMSA), Compañía Agrícola } \\
\text { Bananera del Ecuador S. A. (CABE), FRUSHI } \\
\text { S. A., Agroindustrias San Esteban C. A. } \\
\text { (AGRIESTEBAN), CHOCOLATES NOBOA s. } \\
\text { A., BANAESMERALDAS s. A., BANABONITA s. } \\
\text { A., Compañía de Elaborados de Cacao C. A. } \\
\text { (COLCACAO). }\end{array}$ & $\begin{array}{l}\text { Fertilizantes del Pacífico FERPA- } \\
\text { CIFIC S. A. }\end{array}$ \\
\hline
\end{tabular}

Fuente: Superintendencia de Compañías.

influencia social y política, y ii) son élites que se han «modernizado» diversificando sus actividades. En la matriz se puede observar los intereses y presencia de grupos económicos tan potentes como Noboa o Wong - el cual tiene vínculos con empresas tan importantes como la Favorita, Raybanpac y Fertiza-, y de grupos emergentes como la familia Manobanda que, según las entrevistas, nacieron en los 50 y se han diversificado en varias empresas locales. Al mismo tiempo, el grupo Wong y la familia Manobanda son grupos que tienen influencia en las instituciones estatales y en la Asamblea Nacional, y han sido parte o mantenido vínculos con los partidos políticos de importancia nacional.

A nivel local, además, comparten espacios representación y organización con los propios productores. Las familias Ahón y Wong son parte de la Asociación de Productores de Ciclo Corto (APROCICO) que constituye un gremio de productores como espacio de «sociedad civil». Por ejemplo, en una visita a sus oficinas se pudo observar que en el mismo edificio se encuentran la Asociación de Productores de Palma (quevepalma), la Asociación de Productores de Banano (AProban) y la Asociación de Productores de Cacao (QUevecACAO). Todos son espacios donde se juntan los grandes y medianos productores, «discuten» sobre el futuro de su producción o rubro que, a la larga, crea sentidos de pertenencia en su condición de productores y trasladan sus demandas hacia el Estado. Además, las élites intervienen en el Club Deportivo Quevedo e influyen en los contenidos de las televisoras locales o regionales, o en los sistemas de educación local.

Manobanda es de PAIs. Es terrateniente, comerciante explotador de los campesinos que sacamos los productos, le vendemos el cacao, el maíz, el arroz, el café, toda esa vaina. Él tiene 
cachama y tilapia, es dueño de la tierra y comerciante pues. Entonces el gobierno dice que los medios no deben tener otra cosa. Aquí también los comerciantes no deberían tener tierras. [...] Manobanda tiene el comercio y compra el producto, pero tiene una inmobiliaria de casas, el Green Hill que es la escuela para las élites, tiene la acuacultura: cachama y tilapia, tiene palma africana, cacao, banano, teca y ganado. Tiene todo lo que es agroexportación. Todo, todo. En Alianza PAIs ha sido candidato, pero no el viejo, no, el hijo. El hijo, pero es del grupo y el alcalde de Quinzaloma es Manobanda, es del grupo de esos Manobanda. [...] Actúan como mafias y han surgido nuevos ricos de este siglo xxI. (German Jácome, Quevedo, 6 de febrero de 2011)

La influencia de las élites terratenientes y su capacidad de control de las distintas esferas - que abarcan el proceso de producción y circulación de alimentos así como los espacios de producción y reproducción simbólica- le dan una enorme fortaleza al régimen de control y explotación, hoy constituido por el sector agro industrial. La cuenca del río Guayas y la provincia de Los Ríos es una zona en la cual, a diferencia de Chimborazo, las élites terratenientes tienen una importancia política y económica central — dominando los ejes de articulación al mercado mundial a través del cacao/banano/caña/palma-, no solo para la región, sino para el conjunto de la sociedad (Chiriboga, 1980 y Guerrero, 1994). ${ }^{17}$

Los Ríos es una zona en la que los poderes locales no perdieron espacio frente a la iniciativa campesina que presionaba por una reforma agraria, sino que se actualizaron como estructuras de dominación y de control, manteniendo a su favor los cambios económicos y políticos del Estado. Como lo plantean North (1985) y Guerrero (1994), las élites de origen terrateniente han organizado una estructura de poder local que a través de la ampliación de sus redes familiares, la diversificación de sus actividades productivas y la ocupación de distintos espacios de representación, mantienen el control de los recursos productivos y la población.

\section{CONCLUSIONES}

En Ecuador los procesos de reforma agraria no garantizaron la modernización democrática de la sociedad. En su lugar, los intereses de las élites terratenientes organizaron una modernización conservadora garantizando para ellas el mantener — en este caso, ampliar y diversificar- las estructuras de acumulación. Sin embargo, aunque esto puede aparecer como la vía dominante, la acción indígena matizó el proceso a finales del siglo xx y principios del siglo XXI, produciendo una gran democratización política que tampoco parece haber resuelto los problemas de la gran propiedad.

En el caso de la Costa, nos interesa resaltar que el carácter conservador del proceso de modernización fue bastante más radical. Contradictoriamente, a pesar de que el modelo de agroindustria y agronegocios constituyen una promesa d[e desarrollo, ergo, democratización de la sociedad; el avance de las relaciones salariales, la gran propiedad agroindustrial y el mayor vínculo al mercado de exportaciones y agronegocios, no garantizan tal democratización local o una mejor posición de una agenda campesina. Al contrario, la integración temprana de la región al mercado de exportación fortaleció los intereses de las plantaciones sobre la tierra y el control de la mano de obra; fortaleciendo la estructura y posición de las élites dominantes frente a la iniciativa y presión campesina. 


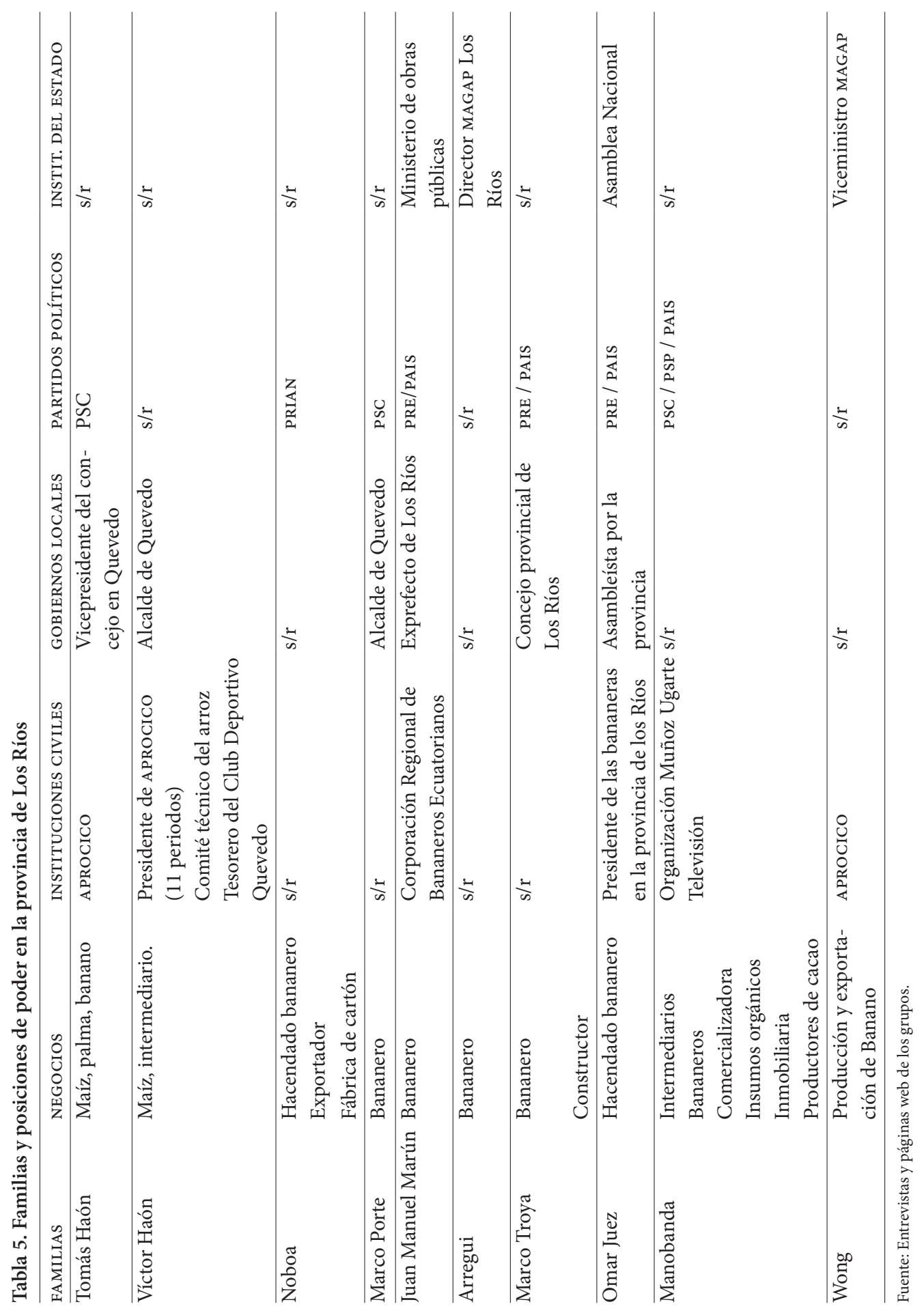


Si bien actualmente los mecanismos de control no son los mismos que antes de las leyes de reforma agraria, éstos se han modernizado bajo un régimen de explotación en el que, en la Costa, la figura de las élites terratenientes no ha retrocedido, sino que han ocupado las distintas esferas de la reproducción social. Tal como lo han mostrado los distintos testimonios, el «hacendado» es una figura pública que controla no solo la producción y circulación de alimentos, sino que además controla la representación política y la reproducción cultural e ideológica. Esta es una capacidad de influencia que termina creando un cerco sobre las iniciativas campesinas y construye una «infraestructura institucional» para la participación activa de los campesinos en el modelo de producción.

Por otro lado, el desarrollo del capitalismo en el campo o el capitalismo en el agro, no es una estructura o dinámica abstracta, sino que en el Ecuador está fuertemente representado por actores o élites — susceptibles a la ley y al control estatal- que tienen la libertad de ejercer violencia sobre los campesinos y de mantener su presión sobre la tierra; combinan el ejercicio de la violencia y «despojo» con la constitución de una red de intereses e instituciones que pueden ejercer su control sobre el Estado y las esferas de representación política y social desde donde organizan las esferas de reproducción económica.

En oposición a esta capacidad de las élites terratenientes en la Costa, la experiencia de Chimborazo nos muestra la importancia de la organización. En términos de Moore, aunque las élites terratenientes también lograron mantener la propiedad sobre las mejores tierras y modernizar sus actividades económicas, la agenda indígena y sus alianzas exitosas han logrado profundizar los procesos de democratización política y económica. Éste no es o no fue un resultado menor, el impulso del movimiento indígena no solo se tradujo en una democratización y debilitamiento de las fronteras étnicas que ha permitido la mayor inclusión indígena. El impulso del movimiento indígena levantó un proyecto de sociedad que está formalizado en la constitución del 2008 y que, a pesar de los límites que ha encontrado en el gobierno de Rafael Correa, será parte de la disputa política entre los sectores indígenas/campesinas y la agroindustria que tiene su origen en la vieja hacienda y plantación.

\section{NOTAS}

1 Este trabajo es un resumen de mi tesis de maestría que lleva el mismo nombre y que puede leerse entera en el repositorio de la Universidad Andina Simón Bolívar de Quito.

2 La fecha más certera sería el 2006, porque desde el 2007 será el gobierno de Rafael Correa el que asuma el rol de oposición contra el neoliberalismo; sin embargo, la constitución del 2008 recoge un conjunto de demandas que son resultado de su impulso democratizador.

3 Las acciones de protesta en las calles y en articulación con otros movimientos sociales -jóvenes, mujeres, trabajadores públicos- permitieron contener varias de las reformas neoliberales más importantes: contuvieron efectivamente el alza de pasajes y la eliminación de subsidios al gas y la gasolina, en 1994 lograron revertir o ganar la consulta popular frente a la Ley Trole, negociaron las inversiones en política agraria, impulsaron programas de apoyo al desarrollo del campo, impulsaron instituciones particulares de crédito, salud y educación indígena, ampliaron el margen de reconocimiento de derechos.

4 Desde 1996 el MP-PK controla 4 o 5 gobiernos provinciales - Cotopaxi, Chimborazo, Zamora, Morona Santiago, Tungurahua-, entre 20 y 26 cantones y un número indeterminado de Juntas Parroquiales. 
5 En el 2003, conjuntamente con el Movimiento Popular Democrático (MPD) y el Partido Sociedad Patriótica (PSP), llevaron a Lucio Gutiérrez a la presidencia.

6 Vale resaltar que en los 90 confluyen también las organizaciones indígenas de la Amazonía y la reconversión de otras organizaciones indígenas campesinas, pero en este punto solo resaltaremos la Sierra, porque la consolidación de las organizaciones amazónicas tiene otros caminos.

7 En el Ecuador, el debate en torno a las vías de modernización sigue el debate de Lenin con referencia a si es un vía campesina o farmer (Guerrero, 1984), vía prusiana o junker (Quintero, 1991) o una iniciativa burguesa (Barsky, 1984). Preferimos las posiciones de Velasco (1979), que se inspira en B. Moore y piensa el proceso de modernización como una relación de fuerzas propia al desarrollo de las relaciones sociales de producción de la época; o North (1985) que inspirada en E. E. P. Thompsom observa una lucha de clases «sin clases» o una disputa en donde las clases - burgueses, industriales y terratenientes, así como trabajadores- no están completamente diferenciadas unas de las otras.

8 Para Moore (1969), el punto de referencia es la eliminación o ruptura de las viejas formas de acumulación y de control de las sociedades feudales como requisito indispensable para el avance del capitalismo industrial.

9 Cuando hablamos de instituciones materiales y simbólicas, asumimos una entrada desde la Economía Moral inspirada por Thompsom (1980), para la cual, además de la presión que ejerce el mercado o el capital sobre los campesinos y la posición de las élites en el proceso, también son importantes los contenidos simbólicos y culturales o las perspectivas de los campesinos sobre el cambio, los acuerdos con las élites, el sentido de la justicia (Brooke, 1993).

10 Tomamos el planteamiento de Mills (1987) y hablamos de élites terratenientes, mas no de clases - simplemente terratenientes o hacendados- porque constituyen una estructura de poder que no se compone exclusivamente de hacendados o terratenientes, sino que disponen de una compleja red de instituciones no formales que les permite mantener una influencia y control sobre otros sectores o clases sociales y sobre el propio Estado.

11 Uggen (1993, p. 81) crea un «índice de violencia rural» para representar la lucha por la tierra y las ocupaciones que las organizaciones campesinas promovidas por el PCE que se realizaron entre 1960 y 1963, previa a la ley de Reforma Agraria y Colonización de 1964. En ésta, registra 33 conflictos, de los cuales 8 se realizan en Los Ríos.

12 En el caso de las organizaciones campesinas/sindicales de la Costa: en 1966 se fundaron la Asociación de Campesinos Agrícolas del Litoral (ACAL) afiliada a la CEDoc, y la Asociación de Campesinos Agrícolas del Ecuador (ACAE) afiliada a la CTE; en 1968 ambas organizaciones fundaron el Frente Unido para la Reforma Agraria (FURA); en 1970 los sembradores de arroz se organizan en la Federación Nacional de Cooperativas Arroceras (FENACAPOR). La Federación Nacional de Organizaciones Campesinas (FENOC), que tuvo un origen católico en 1938; en 1975 la acción de los socialistas arrebata la dirección de la organización y la orienta a la lucha por la tierra. En el caso de las organizaciones indígenas: en los 70 se organizan en comunas los tsáchilas; en 1964 se crea la Federación Shuar; ese mismo año los saraguros constituyen el Jatun Cabildo; en 1969, en el Napo surge la ForN; en 1973 los chachis de Esmeraldas formaron una prefederación; en 1972 se crea la ECUARUNARI; en 1986 aparece la Confederación de Nacionalidades Indígenas del Ecuador (CONACNIE) (Quintero y Silva, 1995, pp. 329-335; Guerrero y Ospina, 2003, p. 26).

13 Con esto me refiero a que los hacendados no están presentes o tienen un rol marginal en los testimonios o las entrevistas realizadas para el trabajo.

14 Aunque en la mayor parte de entrevistas se afirma la eliminación de la hacienda y una creciente eliminación de la gran propiedad, la información que disponemos de los censos agropecuarios de 1954, 1974 y el 2001 es contrastante. Los censos muestran que en Chimborazo la distribución de la tierra, en rasgos generales, mantiene la dualidad minifundio-latifundio. Si bien la gran propiedad hoy tiene menos control proporcional de la tierra (en 1950 el 63\%, en 1974 el 60\% y en el 2001 el 42\%), hasta el 2001 el número de unidades productivas agropecuarias, UPA, mayores de 100 hectáreas y su control sobre el número de hectáreas no ha variado significativamente (320 en 1954; 397 en 1974; 367 en el 2001). Lo 
notable es el crecimiento de la superficie en explotación, entre 1954 y el 2001 crece en más de 150.000 ha, y el crecimiento de las pequeñas propiedades menores de 10 ha en más de 46.000 nuevas UPA -un sector que constituye el $92 \%$ de las UPA y donde la franja de o a 5 ha en el 2001 es por sí sola el $47 \%$ de las UPA, 19.595 UPA que controlan apenas el 6,7\% de la tierra- y la consolidación de una nueva franja de medianos productores entre 10 y 100 ha que hoy controlan el $26 \%$ de superficie, cuando en 1974 apenas representaban el 5,2\% de las UPA y controlaban apenas el 13\% de la tierra (Herrera, 2014).

15 Anthony Bebington (1992) observa que a pesar de la crisis de los años 8o, la cual se tradujo en un enorme descenso de inversiones por parte del Estado, los indígenas de Chimborazo lograron enormes avances al punto de convertirse en los «ganadores» de la misma década.

16 Es importante resaltar que la Costa originalmente fue una zona región de comunidades indígenas dispersas que se integraron a la lógica del mercado rápidamente, y aunque las migraciones de la población indígena fueron ocupando el espacio, la comunidad debió recrearse permanentemente. Por ejemplo, El Empalme se constituyó en los 50 cuando se construyó la vía Manta-Quevedo; las primeras familias que migraron ocupaban extensiones medias de terreno -50 ha o más- y luego se iban ampliando a través de redes de parentesco: hermanos, primos, tíos, invitados a migrar. Así, los recintos se fueron componiendo con el tiempo como «centralidades demográficas» de familias dispersas, pero que no llegaron a constituir centros poblados y comunidades territoriales (Herrera, Cerezal y Capelo, 2003). 17 Aunque la agroindustria se caracteriza por el control de la gran propiedad, el censo agropecuario del 2001 muestra que en la estructura productiva hay una enorme cantidad de pequeños productores probablemente familiares: en el maíz el $23 \%$ de UPA son de o a 5 ha; en el banano el $52 \%$ de UPA tienen menos de 5 ha; en la palma el $29 \%$ de UPA tienen menos de 20 ha; y en la caña el $67 \%$ tienen menos de 2 ha (Herrera, 2014, p. 123).

\section{REFERENCIAS}

Barsky, O. (1984). La reforma agraria ecuatoriana. Quito, Ecuador: FLACso/Corporación Editora Nacional. Bebbington, A. (1992). Actores de una década ganada: tribus, comunidades y campesinos en la modernidad, Quito, Ecuador: COMUnIDEc / Abya Yala.

Brook, L. (1992). Explotación y Economía moral en los Andes del sur. Revista Historia Crítica, (6), 77-95. Burgos, H. (1997). Relaciones Interétnicas en Riobamba. Quito, Ecuador: Corporación Editora Nacional. Carrasco, H. (1993). Democratización de los poderes locales y levantamiento indígena. En J. Almeida (Ed.), Sismo Étnico en el Ecuador (s. p.). Quito, Ecuador: Abya Yala.

Contreras, C. (1994). Guayaquil y su región en el primer boom cacaotero (1750-1820). En J. Maiguashca (Ed.), Historia y región en el Ecuador (1830-1930) (s. p.). Quito, Ecuador: Corporación Editora Nacional.

Cueva, A. (1981). El proceso de dominación política en el Ecuador. Quito, Ecuador: Editorial Alberto Crespo Encalada.

Chiriboga, M. (1980). Jornaleros y gran propietarios en 135 años de exportación cacaotera. Quito, Ecuador: Concejo Provincial del Pichincha / CIEse.

Dubly, A. (1993). Desalojos y despojos: Conflictos agrarios en el Ecuador 1983-199o. Quito, Ecuador: Editorial El Conejo.

González Casanova, P. (2006). Sociología de la explotación. Buenos Aires, Argentina: Consejo Latinoamericano de Ciencias Sociales, CLAcso.

Guerrero, A. (1984). Haciendas, capital y lucha de clases andina: disolución de la hacienda serrana y lucha política en los años 1960-64. Quito, Ecuador: Editorial El Conejo.

Guerrero, A. (1994). Los oligarcas del cacao. Ensayo sobre la acumulación originaria en el Ecuador: 
Hacendados, cacaoteros, banqueros, exportadores y comerciantes de Guayaquil. Quito, Ecuador: Editorial El Conejo.

Herrera, S. (2009). Los movimientos y organizaciones frente al gobierno y Estado. Documento presentado para el proyecto Movimientos sociales en el Ecuador de Rafael Correa. Sin publicación. Instituto de Estudios Ecuatorianos.

Herrera, S., Cerezal M. y Capelo R. (2003). Plan de desarrollo local de las organizaciones campesinas del Empalme. Quito, Ecuador: Fotaena / Fundación María Luisa Gómez de la Torre.

Ibarra, A. (1992). Los indígenas y el Estado en el Ecuador. Quito, Ecuador: Editorial Abya Yala.

Ibarra, H. (1999). Intelectuales indígenas, neoindigenismo e indianismo en el Ecuador. Ecuador Debate, (48), 71-94.

Jácome, G., Landívar, N., Macías, M. y Cueva, V. (2008). Desplazados por la agroexportación. La concentración de la tierra por multipropiedad y fracturación: el caso de Quevedo. En F. Brasell, M. Laforge, y S. Herrera (Eds.), ¿Reforma Agraria en el Ecuador? Viejos temas, nuevos argumentos (pp. 133-152). Quito, Ecuador: Sistema de Investigaciones sobre la Problemática Agraria en el Ecuador, SIPAE.

Korovkin, T. (2008). La reforma agraria y las comunidades indígenas campesinas en Chimborazo. En L. North y J. D. Cameron (Eds.), Desarrollo rural y neoliberalismo. Ecuador desde una perspectiva comparativa (pp. 165-180). Quito, Ecuador: Universidad Andina Simón Bolívar / Corporación Editora Nacional.

Larrea, C. (2006). Hacia una historia ecológica del Ecuador. Quito, Ecuador: Corporación Editora Nacional.

Lautaro, O. (1983). Clientelismo y microoligarquía en la cuenca del Guayas. Ecuador Debate, (3), 35-52.

Lentz, L. (1987). Migración e identidad étnica: la transformación histórica de una comunidad indígena en la Sierra ecuatoriana. Quito, Ecuador: Abya Yala.

Martínez, L. (2003). Dinámicas rurales en el subtrópico. Quito, Ecuador: Centro Andino de Acción Popular, CAAP.

Moore, B. (1973). Los orígenes de la dictadura y de la democracia. El señor y el campesino en la formación del mundo moderno. Barcelona, España: Ediciones Península.

North, L. (1985). Implementación de la política económica y la estructura del poder político en el Ecuador. En L. Lefeber (Ed.), La economía política del Ecuador: campo, región y nación (pp. 425-458). Quito, Ecuador: Corporación Editora Nacional.

North, L. Wade, A. K. y Coep, R. B. (2008). Conflictos por tierras rurales y violación de derechos humanos en el Ecuador. En L. North y J. D. Cameron (Eds.), Desarrollo rural y neoliberalismo: Ecuador desde una perspectiva comparada (pp. 147-164). Quito, Ecuador: Universidad Andina Simón Bolívar / Corporación Editora Nacional.

Ospina, P. y Guerrero, F. (2003). El poder de la comunidad. Ajuste estructural y movimiento indígena en los Andes ecuatorianos. Buenos Aires, Argentina: CLACSO-ASDI.

Ospina, P., Andrade, M., Herrera, S., Jácome, P., Sánchez, P. y Maldonado Ruiz, L. (2008). Mapeo de actores y análisis de poder para el ejercicio de derechos de los pueblos indígenas del Ecuador. Quito, Ecuador: Instituto de Estudios Ecuatorianos / Oxfam.

Quintero, R. y Silva, E. (1991). Ecuador: una nación en ciernes. Quito, Ecuador: FLAcso.

Ronn, P. (1994). Guayaquil y su región en el segundo boom cacaotero (1870-1925). En J. Maiguashca (Ed). 
Historia y región en el Ecuador (1830-1930) (pp. 251-294) Quito, Ecuador: Corporación Editora Nacional.

Rubio, B. (2008). El dominio del capital tradicional exportador sobre los pequeños productores rurales: el caso de las compañías bananeras. En B. Rubio, F. Campana y F. Larrea, Formas de explotación y condiciones de reproducción de las economías campesinas en el Ecuador (pp. 79-107). Quito, Ecuador: Heifer-Ediciones la Tierra.

Silverman, M. (1986). Variabilidad agraria en la Costa ecuatoriana. En M. Murmis (Ed.), Clase y región en el agro ecuatoriano (pp. 79-104). Quito, Ecuador: Corporación Editora Nacional.

Sylva, P. (1987). Gamonalismo y lucha campesina. Estudio de la sobrevivencia y disolución de un sector terrateniente: el caso de la provincia de Chimborazo 1940-1979 (s. p.). Quito, Ecuador: Ediciones Abya Yala / Flacso.

Uggen, J. F. (1993). Tenencia de la tierra y movilizaciones campesinas: zona de Milagro. Quito, Ecuador: Anden Center for Latin American Studies, ACLAs.

Velasco, F. (1979). Reforma agraria y movimiento campesino indígena en la Sierra. Quito, Ecuador: Editorial El Conejo.

Wright, M. (1987). La élite del poder. México DF, México: Fondo de Cultura Económica. 